\title{
The Application of Thamasett Algorithm in the Calculation on Spinning Force of Biotical Turning Wheel
}

\author{
Yu Yang \\ Changchun University of Science and Technology, China \\ yangyu1983@sina.com
}

Key words:double taper roller; thamasett algorithm; spinning force

Abstract. This thesis is focused on the spinning process experiment of double conical wheel with small fillet radius on various materials and the measurement of spinning force using electrical measuring method. The result of the experiment is very close to the one by thamasett in the axial and tangential direction, which proves that thamasett can be applied to the calculation of spinning force of double conical wheel with small fillet radius. Spinning force is the important basis of spinning process parameter. The application of thamasett in the calculation of double conical wheel provides theoretical basis to the setting of spinning process parameter.

\section{Introduction}

The Spinning force is a key reference to design the process of spinning, selection of spinning machine and design mold. It has big relations among the spinning force and the size of blank, the mechanical properties of materials, thinning ratio, and spinning mode[1-12]. Based on thamasett algorithm theoretically calculated the spinning force produced by double tapered roller to rotundity powerful spinning materials, and on the basis of the experimental test spinning force, proved that thamasett algorithm is only applicable to calculate the spinning force on small fillet radius of biotical turning wheel[13].

\section{Thamasett algorithm}

The assumptions of Thamasett algorithm in biotical turning wheel to the powerful spinning of cylindrical materials.

Biotical turning wheel to the powerful spinning of cylindrical materials as shown in Figure1.

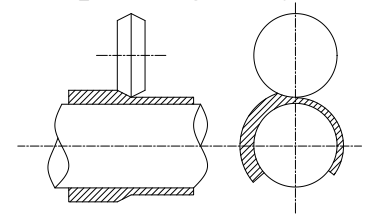

Figure1. Biotical turning wheel to the powerful spinning of cylindrical materials

Thamasett algorithm is a similarity calculation based on the method of rolling force, the difference is that while rolling deformation materials mainly along the direction of flow, but strong rolling toward spin when materials vertical spinning direction[14]. When rolling deformation force for:

$$
P=F_{d} \overline{\sigma_{m}} / \eta_{p}=b_{1} L_{d} \overline{\sigma_{m}} / \eta
$$

Type: $b_{1}$ for deformation area, which have similar width rolling out the width of the board, $L_{d}$ for the contacting arc length of casting die and compression roller; $\overline{\sigma_{m}}$ For the average deformation resistance of deformation material, $\eta$ for deformation efficiency.

In order to make type (1) to rotundity strong spin must do as follows: I assume radius of rounded angle of biotical turning wheel $r_{p}=0$; II .the total spinning force $P$ is perpendicular to the interface between turning wheel and tube blank. Neglect the friction force of deformation zone, Iii, interface approximate as bending rectangle.

Calculation of radial force $P_{r}$ :

$$
P_{r}=b L_{d} \overline{\sigma_{m}} / \eta
$$


Type: $b$ for the floor projection length between turning wheel and interface, $L_{d}$ For the arc length of spinning wheels and tube billet contact cross section, $\Delta h$ For thinning after every turn.

$$
\begin{aligned}
b & \approx \Delta \operatorname{tctg} \alpha_{p} \\
L_{d} & \approx \sqrt{R_{p} \Delta h} \\
\Delta t & =f \operatorname{tg} \alpha_{p} \\
P_{r} & =f \operatorname{tg} \alpha_{p} \operatorname{ctg} \alpha_{p} \sqrt{R_{p} \Delta h} \overline{\sigma_{m}} / \eta
\end{aligned}
$$

Thinning $\Delta h$ can be calculated as follow:

$$
\Delta h=f \Delta t_{\Sigma} / l
$$

Type: $f$ for relative axial feeding of tube billet and the spinning wheel, $l$ for the compression deformation area length, $\Delta t_{\Sigma}$ for total thinning ratio of tube wall thickness[15].

When the cylindrical parts are spinning strongly, the main deformation for the spinning is from wall thickness and the length of the pipe, and the increase of the lateral deformation is very small.

Normally, diameter work piece is not equal diameter, therefore must be show by inducing radius $R_{y}$ :

$$
\begin{aligned}
& R_{y}=2 R R_{y} /\left(R+R_{y}\right) \\
& L_{d} \approx \sqrt{R_{y} f \operatorname{tg} \alpha_{p}}
\end{aligned}
$$

Thus to radial force for:

$$
P_{r}=\Delta \operatorname{tctg} \alpha_{p} \sqrt{R_{y} f \operatorname{tg} \alpha_{p}} \bar{\sigma}_{m} / \eta
$$

Radial $P_{r}$ and axial force $P_{z}$ are mutually perpendicular, therefore, the axis forces for:

$$
P_{z}=\Delta t \overline{\sigma_{m}} \sqrt{R_{y} f \operatorname{tg} \alpha_{p}} / \eta
$$

Also can be determining the tangential force $P_{i}$ for:

$$
P_{i}=\Delta t f \overline{\sigma_{m}} / \eta
$$

Calculate the radial, axial and cutting force to each of the three vertical, but the double tapered type spiral spinning wheel cylinder parts of total deformation force:

$$
P=P_{i} \sqrt{2 R_{y} / f \sin 2 \alpha_{\gamma}+1}
$$

By type (13), the main factors which influence spinning force is the processing parameters of turning wheel, thinning $\Delta t$ and feeding $f$.

Spinning wheels are the main tools in spinning process, also an essential factors of make the spinning process has achieved good effect. When working with blank, it direct hold tremendous contact pressure, severe friction and working temperature. Parameters of Spinning wheel will directly affect the quality of the work piece and the forming of spinning force. Based on surface after nit riding process of HSS as spinning wheel material, it has the merit of less heat sensitivity, hardness and long working life etc.

Thinning is directly affecting the pressure of powerful spinning and spinning accuracy. It also relevant with thinning ratio and pass, pass and thinning ratio will cause instability accumulation of work piece, surface will appear peeling easily. The ratio of thinning and pass will cause uneven thickness of work piece; the work piece may appear cracks because of insufficient deformation of work pieces.

Feeding has certain effect on the swell-shrink of work piece diameter and quality of work piece.

\section{Spinning force measurement text}

Using biotical turning wheel test the spinning force among a variety of materials. Experiments to verify the applicability of the calculation formula, we only change 
feeding $\Delta t$, thinning $f$, and contact Angle $\alpha_{p}$, by using the electricity measure method to test the spinning force in a variety of materials. The experimental parameters such as show in table 1 . The experimental results such as shown in table 2 .

Table 1 Experimental parameters

\begin{tabular}{|c|c|c|c|c|c|}
\hline Capacity & 5000 & $\begin{array}{c}\text { Spindle motor } \\
\text { power }\end{array}$ & $250 \mathrm{KN}$ & $\begin{array}{c}\text { Maximum spindle } \\
\text { speed }\end{array}$ & $200 \mathrm{r} / \mathrm{min}$ \\
\hline $\begin{array}{c}\text { Maximum } \\
\text { clamping force }\end{array}$ & $800 \mathrm{KN}$ & Mandrel diameter & $34.6 \mathrm{~mm}$ & $\begin{array}{c}\text { Rotary wheel } \\
\text { sensor accuracy }\end{array}$ & $10 \mu \mathrm{m}$ \\
\hline $\begin{array}{c}\text { Repeat positioning } \\
\text { accuracy rotary } \\
\text { wheel }\end{array}$ & $0.16 \mathrm{~mm}$ & $\begin{array}{c}\text { Hydraulic servo } \\
\text { valve responsive }\end{array}$ & $50 \mathrm{~Hz}$ & $\begin{array}{c}\text { Repeat accuracy of } \\
\text { servo valve }\end{array}$ & $0.1 \%$ \\
\hline
\end{tabular}

Table 2. Test on the spinning force on variety of materials

\begin{tabular}{|c|c|c|c|c|c|c|c|c|}
\hline \multirow{3}{*}{} & materials & $\mathrm{d}$ & $\mathrm{D}$ & $\begin{array}{c}\text { Contact } \\
\text { angle }\end{array}$ & $\begin{array}{c}\text { Amount of } \\
\text { feed }\end{array}$ & $\begin{array}{c}\text { Primary } \\
\text { wall-thickn } \\
\text { ess }\end{array}$ & $\begin{array}{c}\text { Wall-thickn } \\
\text { ess }\end{array}$ & $\begin{array}{c}\text { Thinning } \\
\text { ratio }\end{array}$ \\
\hline \multirow{3}{*}{$\Delta t$} & $\mathrm{StVIIu}$ & $39.75 \mathrm{~mm}$ & $80 \mathrm{~mm}$ & $25^{\circ}$ & $0.1 \mathrm{~mm} / \mathrm{r}$ & $1.19 \mathrm{~mm}$ & $0.92 \mathrm{~mm}$ & $22.7 \%$ \\
\cline { 2 - 9 } & $\mathrm{StVIII}$ & $39.75 \mathrm{~mm}$ & $80 \mathrm{~mm}$ & $25^{\circ}$ & $0.1 \mathrm{~mm} / \mathrm{r}$ & $1.19 \mathrm{~mm}$ & $0.73 \mathrm{~mm}$ & $38.7 \%$ \\
\cline { 2 - 9 } & $\mathrm{StVIII}$ & $39.75 \mathrm{~mm}$ & $80 \mathrm{~mm}$ & $25^{\circ}$ & $0.1 \mathrm{~mm} / \mathrm{r}$ & $1.17 \mathrm{~mm}$ & $0.45 \mathrm{~mm}$ & $61.5 \%$ \\
\hline \multirow{3}{*}{$f$} & $\mathrm{StVIIu}$ & $39.75 \mathrm{~mm}$ & $80 \mathrm{~mm}$ & $25^{\circ}$ & $0.1 \mathrm{~mm} / \mathrm{r}$ & $1.19 \mathrm{~mm}$ & $0.73 \mathrm{~mm}$ & $38.7 \%$ \\
\cline { 2 - 9 } & $\mathrm{StVIIu}$ & $39.75 \mathrm{~mm}$ & $80 \mathrm{~mm}$ & $25^{\circ}$ & $0.2 \mathrm{~mm} / \mathrm{r}$ & $1.18 \mathrm{~mm}$ & $0.74 \mathrm{~mm}$ & $37.3 \%$ \\
\cline { 2 - 9 } & $\mathrm{StVIIu}$ & $39.75 \mathrm{~mm}$ & $80 \mathrm{~mm}$ & $25^{\circ}$ & $0.3 \mathrm{~mm} / \mathrm{r}$ & $1.19 \mathrm{~mm}$ & $0.75 \mathrm{~mm}$ & $37.0 \%$ \\
\hline
\end{tabular}

\begin{tabular}{|c|c|c|c|c|c|c|c|c|c|}
\hline \multicolumn{2}{|c|}{ material } & $d$ & \multicolumn{2}{|c|}{$D$} & act angle & \multicolumn{2}{|c|}{ Amount of feed } & \multicolumn{2}{|c|}{$\begin{array}{c}\text { Primary } \\
\text { wall-thickness }\end{array}$} \\
\hline \multirow{2}{*}{\multicolumn{2}{|c|}{$\frac{\text { Mst3u }}{\text { Mst3u }}$}} & $148.95 \mathrm{~mm}$ & \multirow{2}{*}{\multicolumn{2}{|c|}{$\frac{175 \mathrm{~mm}}{175 \mathrm{~mm}}$}} & $25^{\circ}$ & \multicolumn{2}{|c|}{$0.132 \mathrm{~mm} / \mathrm{r}$} & \multicolumn{2}{|c|}{$5.95 \mathrm{~mm}$} \\
\hline \multirow{2}{*}{\multicolumn{2}{|c|}{$\frac{\text { Mst3u }}{\text { Mst3u }}$}} & $202.80 \mathrm{~mm}$ & \multirow{2}{*}{\multicolumn{2}{|c|}{$\begin{array}{l}175 \mathrm{~mm} \\
177 \mathrm{~mm}\end{array}$}} & $25^{\circ}$ & \multicolumn{2}{|c|}{$0.270 \mathrm{~mm} / \mathrm{r}$} & \multicolumn{2}{|c|}{$\frac{5.90 \mathrm{~mm}}{5.70 m}$} \\
\hline & & \multirow{2}{*}{$\frac{99.10 \mathrm{~mm}}{106.00 \mathrm{~mm}}$} & & & $27^{\circ}$ & \multirow{2}{*}{\multicolumn{2}{|c|}{$\frac{0.522 \mathrm{~mm} / \mathrm{r}}{1.010 \mathrm{~mm} / \mathrm{r}}$}} & & $0 \mathrm{~mm}$ \\
\hline \multicolumn{2}{|l|}{ Mst3u } & & \multicolumn{2}{|c|}{$202 \mathrm{~mm}$} & $27^{\circ}$ & & & & $0 \mathrm{~mm}$ \\
\hline \multirow{4}{*}{$\alpha_{p}$} & $\mathrm{StVIllu}$ & $39.75 \mathrm{~mm}$ & $80 \mathrm{~mm}$ & $12^{\circ}$ & $0.2 \mathrm{~mm} / \mathrm{r}$ & $1.19 \mathrm{~mm}$ & & & $35.3 \%$ \\
\hline & StVIllu & $39.75 \mathrm{~mm}$ & $80 \mathrm{~mm}$ & $25^{\circ}$ & $0.2 \mathrm{~mm} / \mathrm{r}$ & $1.19 \mathrm{~mm}$ & & & $42.0 \%$ \\
\hline & StVIllu & $39.75 \mathrm{~mm}$ & $80 \mathrm{~mm}$ & $30^{\circ}$ & $0.2 \mathrm{~mm} / \mathrm{r}$ & $1.19 \mathrm{~mm}$ & & & $42.8 \%$ \\
\hline & $\mathrm{StVIllu}$ & $39.75 \mathrm{~mm}$ & $80 \mathrm{~mm}$ & $35^{\circ}$ & $0.2 \mathrm{~mm} / \mathrm{r}$ & $1.18 \mathrm{~mm}$ & & & $44.1 \%$ \\
\hline
\end{tabular}

\begin{tabular}{|c|c|c|c|c|c|c|c|}
\hline & \multirow{2}{*}{ material } & \multicolumn{3}{|c|}{ Measurements } & \multicolumn{3}{|c|}{ theoretical value } \\
\hline & & axial force & radial force & twisting force & axial force & radial force & twisting force \\
\hline \multirow{3}{*}{$\Delta t$} & StVIIu & $902 \mathrm{~N}$ & $1127 \mathrm{~N}$ & $129 \mathrm{~N}$ & $1529 \mathrm{~N}$ & $3273 \mathrm{~N}$ & $120 \mathrm{~N}$ \\
\hline & StVIIIu & $1470 \mathrm{~N}$ & $1519 \mathrm{~N}$ & $137 \mathrm{~N}$ & $1578 \mathrm{~N}$ & $3381 \mathrm{~N}$ & $111 \mathrm{~N}$ \\
\hline & $\mathrm{StVIIIu}$ & $2362 \mathrm{~N}$ & $2166 \mathrm{~N}$ & $211 \mathrm{~N}$ & $2479 \mathrm{~N}$ & $5321 \mathrm{~N}$ & $137 \mathrm{~N}$ \\
\hline \multirow{3}{*}{$f$} & StVIIu & $1470 \mathrm{~N}$ & $1519 \mathrm{~N}$ & $137 \mathrm{~N}$ & $1578 \mathrm{~N}$ & $3381 \mathrm{~N}$ & $111 \mathrm{~N}$ \\
\hline & $\mathrm{StVIIu}$ & $1784 \mathrm{~N}$ & $1950 \mathrm{~N}$ & $210 \mathrm{~N}$ & $1705 \mathrm{~N}$ & $3646 \mathrm{~N}$ & $170 \mathrm{~N}$ \\
\hline & StVIIu & $2274 \mathrm{~N}$ & $2528 \mathrm{~N}$ & $352 \mathrm{~N}$ & $2323 \mathrm{~N}$ & $4978 \mathrm{~N}$ & $286 \mathrm{~N}$ \\
\hline \multirow{4}{*}{$\alpha_{p}$} & StVIlu & $1695 \mathrm{~N}$ & $2871 \mathrm{~N}$ & $336 \mathrm{~N}$ & $1980 \mathrm{~N}$ & $9349 \mathrm{~N}$ & $297 \mathrm{~N}$ \\
\hline & StVIlu & $2078 \mathrm{~N}$ & $2852 \mathrm{~N}$ & $290 \mathrm{~N}$ & $2410 \mathrm{~N}$ & $5164 \mathrm{~N}$ & $233 \mathrm{~N}$ \\
\hline & StVIlu & $2626 \mathrm{~N}$ & $2176 \mathrm{~N}$ & $255 \mathrm{~N}$ & $2323 \mathrm{~N}$ & $4018 \mathrm{~N}$ & $199 \mathrm{~N}$ \\
\hline & StVIIu & $3254 \mathrm{~N}$ & $2185 \mathrm{~N}$ & $358 \mathrm{~N}$ & $2626 \mathrm{~N}$ & $5155 \mathrm{~N}$ & $279 \mathrm{~N}$ \\
\hline
\end{tabular}

In order to verify Spinning Tube diameter, thickness and size of the thamasett algorithm theoretical values, this paper only change the pieces of wall thickness and diameter of the spinning conditions, on the same kinds of materials of different thickness, diameter of the cylindrical pieces were axial spinning experiments, and theoretical value and measured values were compared, as shown in Table 3. The schematic diagram is shown in Figure2.

Table 3. Different thickness, the diameter of the cylinder axial pressure value

\begin{tabular}{|c|c|c|c|c|}
\hline material & Wall-thickness & Thinning ratio & Testing radial force & Testing axial force \\
\hline Mst3u & $4.94 \mathrm{~mm}$ & $24.5 \%$ & $10339 \mathrm{~N}$ & $12544 \mathrm{~N}$ \\
\hline Mst3u & $4.73 \mathrm{~mm}$ & $19.8 \%$ & $13377 \mathrm{~N}$ & $16954 \mathrm{~N}$ \\
\hline Mst3u & $4.00 \mathrm{~mm}$ & $29.8 \%$ & $45031 \mathrm{~N}$ & $34888 \mathrm{~N}$ \\
\hline Mst3u & $4.70 \mathrm{~mm}$ & $35.6 \%$ & $59604 \mathrm{~N}$ & $67914 \mathrm{~N}$ \\
\hline
\end{tabular}




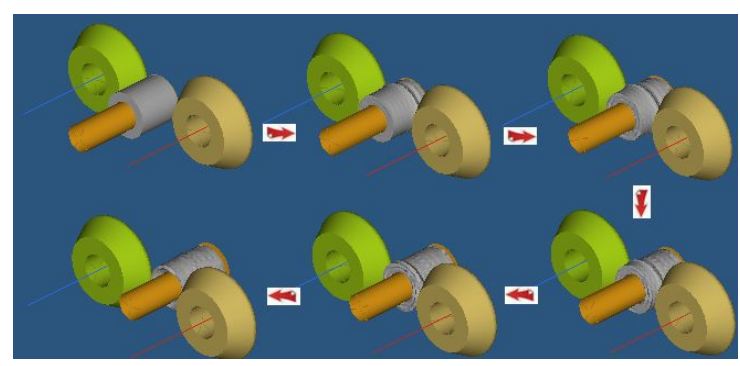

Figure2 Spin diagram

From the experiment results, the theoretical value by using thamasett algorithm agree $\mathrm{w}$ ith the practical measurement value, especially the axial force and tangential force are most closely to the practical value. But the spinning force from different direction and the total spinning force contain the main influencing factors, and three components are proportional with absolute reducing thickness of wall thickness and the average deformation of material; inversely proportional to the deformation efficiency of materials which relate to internal and external contact surface friction[16]. At the same time, the radial and axial force also have the relationship with the longitudinal feed, radius of curvature, and the square root trian gle of contact Angle of spinning force. However, the formula for calculating the spin force only applies to the stability of the spinning process, that is to say the metal in the axial continuous flow stably. Through measuring the curve shown on Porto should be a horizonta 1 line. But this only happened in the condition of no accumulation of material and local $\mathrm{i}$ nstability, or the metal will form the metal accumulation because of non-fluency, will not only change the geometric relationships, and will change its deformation, thus changing nee ds[17]. This is the reason on difference measurements between theoretical value and testing value.

\section{Conclusions}

A comprehensive analysis of the above, from the experimental results also can see whe $\mathrm{n}$ we calculating the spinning force on the thick wall and large diameter cylinder parts, na mely the spinning wheel in large round angle-radius spin to rotundity are spinning, the spin ning force will appear error, so thamasett is applicable to small fillet radius of biotical turn ing wheel of spinning force calculation.

\section{References}

[1] McQueen H J.Metal forming, Industrial mechanical computational and microstuctural[J]. Journal of materals processing technology.1993.37:31-36.

[2] Zhao Yunhao,Li Yanli.Spinning Technology and Application.Machinery Industry Press. 2008:5-6.

[3] Matsunok. Recent Research and Development in Metal Forming in Japan, J, Mater, Process, Technol, 1997.06:1-3.

[4] Anon. Metal spinning in the auto motive industry, Sheet Metal Industries.1995.12:13-18.

[5] Xue Kemin, Wang Zhen, Lu Yan. Elasto-plastic FEM Analysis and Experimental Study of Diametral Growth in Tube Spinning, J, Mater, Process, Technol, 1997.69:172-175.

[6] WANG Z T, XIE S S, JIN Q J. Elasto-plastic finite element analysis of hydrostatic extrusion with various mathematically contoured dies, Proceedings of the 24th International Machine Tool Design and Research Conference, eds, Davies BJ, Manchester, 1983.08(31):51-58.

[7] HAYAMA, Hiroaki KUDO. Experimental Study of Tube Spinning. Bulletion of JSME. 1979.22:769-775.

[8] Zhang Ning,Tan Wen,LiYonghua.Numerical Simulation and Spinning Force Analysis for Tube 
Stagger Spinning.Transactions of Shenyang Ligong University. 2009.28:55-58.

[9] Hu Lijin,Zhan Mei,Huang Liang.Prediction of radial crack of the workpiece during the splitting spinning based on ductile fracture criteria.Journal of Plasticity Enginnering. 2009.04:22-24.

[10] Li Zenghui,Wen Shubin,Han Dong.The Study of Spinning Precision Control for Thin Wall Cylinder with Large Length-diameter Ratio.China Metal Forming Equipment\&Manufacturing Technology. 2009.04:102-105.

[11] Mao Baiping,Shen Jian.Effects of Spinning Deformation on Microstructure and Properties of 6061 Al-alloy Tube.Hot Working Technology. 2008.37:49-54.

[12] Mu Shaozheng,Han Dong, Yang Yingli.Research on Tube Spinning Process and Propertied of Cast Titanium Alloy.China Metal Forming Equipment\&Manufacturing Technology. 2009.02:98-100.

[13] De Vries M F, Thomson H H. The manufacture of an ancient silver bowl. Journal of applied metalworking, 1980.07:330-382.

[14] C.C.Wong, T.A.Dean and J.Lin. A review of spinning, Shear forming and flow forming processes, International journal of machine toold and manufacture, 2003.43:1419-1435.

[15] ZhaoYunhao, LiYanLi, spinning technology and application, Beijing: mechanical industry press, 2008:99.

[16] Hayana, Hiroaki Kudo. Experimental study of tube spinning. Bulletin of the jsme, 1979.22:769-775.

[17] Jahazi M, Ebrahimi G. The influence of flow-forming parameters and microstructure on the quality of a D6AC steel. Journal of materials processing technology, 2000.103:362-366. 